\title{
Gênese e Redefinições do Militantismo Ambientalista no Brasil
}

\author{
Wilson José Ferreira de Oliveira
}

\section{APRESENTAÇÃO}

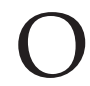

s anos 1980 têm sido caracterizados pela literatura sobre o ambientalismo como o marco do aparecimento de novas modalidades de militantismo na defesa de causas ambientais, as quais se distinguem, entre outros fatores, pela ruptura em relação às práticas militantes que predominavam no período anterior. Nesse sentido, uma das principais transformações que tem sido salientada é a tendência geral de institucionalização da ação associativa a fim de regularizar seu acesso aos espaços e processos formais de produção de políticas públicas, além de profissionalizar seus integrantes e suas atividades. Segundo esses estudos, a participação regular das associações ambientalistas em instâncias formais de proteção ambiental esteve associada ao recrutamento de militantes e dirigentes dotados de elevada formação técnica e científica e à utilização de competências de expertise adquiridas por meio da formação universitária, como um dos principais recursos militantes nas intervenções públicas de tais organizações, possibilitando a emergência de um novo campo de exercício profissional. Em relações às diferenças de abordagem, tanto a literatura nacional quanto a internacional (mais precisamente a européia e a norte-americana) convergem para esse tipo de caracterização do ambientalismo (Loureiro e Pacheco, 1995; Rootes, 1999; Sainteny, 1999; 2000; Ollitrault,

DADOS - Revista de Ciências Sociais, Rio de Janeiro, Vol. 51, nº3, 2008, pp. 751 a 777. 
2001; Anquetin, 2002; Gallet, 2002). Além disso, outros trabalhos têm demonstrado que a importância crescente dos recursos escolares e da legitimidade de expertise nas mobilizações coletivas não parece ser uma característica exclusiva do militantismo ambientalista, podendo ser igualmente observada na defesa dos direitos do homem e de causas humanitárias (Agrikoliansky, 2002; Siméant e Dauvin, 2002), no militantismo sindical (Matonti e Poupeau, 2004; Wagner, 2004), entre outros.

No caso brasileiro, ainda são poucos os trabalhos que focalizam as condições históricas e sociais de emergência e as dinâmicas de transformação das formas de engajamento e de participação na defesa de causas ambientais. Como salientam Alonso e Costa (2002), a partir do final da década de 1980, os estudos sobre essa temática passaram a se concentrar no "desenvolvimento sustentável" e foram produzidos fora das ciências sociais por especialistas das ciências naturais e das humanidades, tais como filósofos, geógrafos, demógrafos, biólogos, agrônomos, jornalistas, entre outros, mas mantendo um viés político, engajado. Com isso, a categoria "movimento ecológico" foi praticamente abandonada pela literatura, passando-se a privilegiar os estudos dos processos de "degradação ambiental", o que conduziu à multiplicação dos estudos sobre os "impactos socioambientais" do desenvolvimento econômico e político e sobre as "estratégias alternativas" representadas pelas mobilizações ambientalistas (Loureiro e Pacheco, 1995). Isso decorre de fatores relacionados à própria dinâmica de configuração das ciências sociais no Brasil: de um lado a emergência e a expansão da formação universitária e profissional no país como indissociáveis do engajamento e da participação política (Dezalay e Garth, 2002; Coradini, 1998; Pécaut, 1990); de outro, a intensificação, nos últimos anos, de sua utilização como instrumento de politização para a atuação profissional em diferentes esferas de atividade (Coradini, 2002). Sendo assim, semelhante ao que tem sido observado em outras situações nacionais (Devaux, 2005a; 2005b), no caso brasileiro, é a forte imbricação entre as abordagens científicas e o debate político, bem como a própria ausência do militantismo como objeto de estudo, que se apresenta como um dos principais problemas de investigação (Oliveira, 2005; 2006).

Este artigo compreende essa problemática de investigação mais geral, referente às condições de emergência e às dinâmicas do militantismo na defesa de causas ambientais. Com base em uma investigação sobre as modalidades de engajamento e de participação em mobilizações e 
organizações ambientalistas entre 1970 e 2004, pretende-se demonstrar que, no caso brasileiro, o contexto político denominado "abertura política" e "redemocratização" constitui um marco do aparecimento de novos padrões de reconversão da formação escolar e universitária em recursos militantes e profissionais para a atuação na "área de meio ambiente". Para evidenciar isso, e em consonância com outros estudos sobre o ambientalismo brasileiro, levanta-se a hipótese de que as mobilizações desenvolvidas nesse contexto têm uma importância destacada para a compreensão do processo de emergência e de consolidação da problemática ambiental no caso do Brasil (Alonso, Costa e Maciel, 2007).

Tal hipótese está sustentada também em estudos sobre outras formas de militantismo, as quais tomam as mobilizações ocorridas naquele período como representativas de um processo mais amplo de diversificação das modalidades de utilização da formação escolar e profissional como instrumento de politização em diferentes esferas de atuação (Mische, 1997; Coradini, 2002). Todavia, isso não quer dizer que o aparecimento dessas novas modalidades de militantismo tenha ocorrido apenas a partir daquele momento. Pelo contrário, elas dão continuidade a certas concepções e práticas militantes que caracterizam o ambientalismo desde o período antecedente (Oliveira, 2005). Por isso, acrescenta-se à referida hipótese o postulado de que, em meio à maior diversificação das modalidades de articulação da formação escolar com o engajamento político, ocorrida durante o contexto de "abertura política", existem também certas continuidades quanto às concepções de sociedade e de política que fundamentam as práticas militantes dos ambientalistas. Tal formulação está embasada em investigações empíricas sobre diferentes tipos de "profissão". Esses estudos têm salientado que as concepções e as práticas associadas à formação e ao exercício "profissional" em diferentes esferas de atividade exigem sobretudo a capacidade de estabelecer um vínculo duradouro entre o "conhecimento escolar" e a "realidade", de modo que a prática profissional é concebida como algo que resulta quase sempre da utilização instrumental de competências adquiridas por meio da formação escolar e universitária com fins de politização nas mais diferentes esferas sociais (Pécaut, 1990; Coradini, 1998; Dezalay e Garth, 2002). Em consonância com isso, neste artigo, o crescimento da quantidade de organizações ambientalistas e a maior difusão da causa ambiental que teve início nos anos 1970 são considerados decorrentes da intensificação da imbricação da formação escolar com o engajamento político em diver- 
sas esferas de atuação e de sua correspondência com uma grande proliferação de organizações e "movimentos sociais" vinculados às mobilizações pela "democratização" (Mische, 1997). Em decorrência, demonstra-se que a participação em organizações e em mobilizações ambientalistas resultou na configuração da defesa do meio ambiente como um militantismo de reconversão de diferentes tipos de formação escolar e universitária em recursos e competências para a ocupação de cargos e postos profissionais em diversas esferas de atividade: estatal, partidária, associativa, acadêmica, religiosa, entre outras.

A construção dessa abordagem defrontou-se também com o problema referente às condições e aos processos sociais, políticos e culturais que tornam possíveis a emergência de mobilizações e protestos coletivos. No tratamento dessa problemática, as análises orientadas pelas teorias da "estrutura de oportunidades" e dos "processos políticos" constituíram um ponto de partida fundamental ao demonstrarem a pertinência do exame das características do contexto político no qual ocorre o ingresso em organizações de movimentos sociais e como tal contexto influencia tanto a estrutura organizacional dos movimentos quanto seus referenciais ideológicos e suas estratégias de ação (McAdam, McCarthy e Zald, 1996; Passy, 1998; Toni, 2001). No que tange à relevância desse ponto de partida, um dos problemas que não encontrou um tratamento adequado no âmbito de tais abordagens é o que diz respeito à apreensão dos processos de engajamento individual (Tarrow, 1988; Mathieu, 2002). Uma das alternativas propostas para contornar essa problemática tem sido investigar as relações entre as particularidades das configurações políticas e as condições e os processos de engajamento individual na defesa de causas coletivas (Fillieule, 2001; Devaux, 2005b). Para dar conta de tal desafio, um dos procedimentos presentes em grande parte da literatura consiste em examinar os recursos e os respectivos vínculos sociais e políticos que conduzem os indivíduos ao engajamento e à permanência no militantismo em diferentes contextos políticos. Com base nessas orientações, levanta-se a hipótese de que a intensificação da utilização instrumental da formação escolar e universitária no âmbito da defesa de causas ambientais está estreitamente relacionada às características particulares dos contextos políticos nacional e internacional, na medida em que o tipo de contexto influencia a conformação dos tipos de causa, ator, recurso e respectivos vínculos associados ao ativismo ambientalista. Nesse sentido, pretende-se evidenciar que, paralelamente à modificação de um contexto de 
"fechamento" do sistema político para outro de "abertura política", ocorreu a transformação do perfil dos ativistas que atuam no ambientalismo, assim como dos tipos de recurso e respectivos vínculos que os conduziram à defesa de causas ambientais: de um lado um militantismo composto por lideranças com origens sociais elevadas, estreitamente ligado às elites econômica, militar, política e cultural e dotado de disposições cosmopolitas adquiridas no universo familiar e reforçadas por sua inserção na esfera internacional; de outro, um militantismo que se caracteriza pelo ingresso de indivíduos com origens sociais mais baixas e heterogêneas, predominantemente vinculados a organizações estudantis, partidárias e a "movimentos sociais" diversificados, e que são os principais protagonistas da aproximação entre as questões ambientais e as lutas sociais e políticas que agitavam o contexto político nacional naquele momento.

O material utilizado como fonte de informação decorre de uma investigação sobre as condições e as lógicas sociais do engajamento e da participação na defesa de causas ambientais no Rio Grande do Sul entre 1970 e 2005 (Oliveira, 2005). Nessa pesquisa, foram realizadas cinqüenta entrevistas biográficas com os dirigentes das principais Organizações Não-Governamentais - ONGs ambientalistas do estado, que nelas ingressaram em diferentes momentos do período considerado, possibilitando a caracterização e a comparação de distintas gerações militantes. Tal material foi complementado pela realização de observações etnográficas da intervenção desses dirigentes em uma série de eventos vinculados à defesa do meio ambiente (reuniões de associações, seminários e congressos, conselhos e comitês de proteção ambiental, entre outros). Os procedimentos metodológicos utilizados para levantamento e análise do referido material concentraram-se na investigação das trajetórias familiar, escolar, ocupacional e militante que os conduziram ao ambientalismo; no exame dos significados e das modalidades de uso da formação escolar associados à sua atuação; e na análise da diversidade de esferas e de redes sociais que contribuíram para a aquisição e a reconversão dos recursos que fundamentam suas concepções e práticas profissionais. O material obtido por meio desses procedimentos levou à identificação de diferentes padrões de carreira que conduzem à atuação profissional na área de meio ambiente nos diferentes contextos políticos considerados. 


\section{A "ELITE DE NATURALISTAS", OS "NATURALISTAS" DA ELITE E A "NOVA MORAL ECOLÓGICA"}

A existência de organizações e de mobilizações voltadas para a defesa de causas ambientais no Brasil não se reduz à década de 1970. Desde o final do século XIX a defesa de parques nacionais e de espécies animais e vegetais passou a ser objeto de formulações governamentais e da ação desenvolvida por associações ambientalistas. Esse é o caso das formulações voltadas para a constituição de "reservas florestais" no início do século XX, da elaboração do Código de Águas e Minas e do primeiro Código Florestal Federal Brasileiro, por volta da implementação da Constituição de 1934, bem como da criação da Sociedade Amigos das Árvores e da Sociedade Amigos de Alberto Torres, respectivamente em 1931 e em 1934 (Bones e Hasse, 2002:22). Tanto a elaboração desses códigos e leis de proteção ambiental quanto a criação das principais associações que atuaram nesse período estão estreitamente relacionadas à realização de conferências e à elaboração de diretrizes internacionais em matéria de proteção ambiental (Svirsky e Capobianco, 1997).

De maneira geral, pode-se dizer que o movimento ambientalista brasileiro anterior à década de 1970 esteve estreitamente vinculado à problemática internacional, surgida na Europa e nos Estados Unidos, da conservação e da preservação de sítios, paisagens e recursos naturais, assim como de espécies animais, florestas, lagos etc. Por outro lado, ainda que sejam raros os estudos sobre a composição social das associações no referido período, observa-se que suas principais lideranças estavam vinculadas aos setores técnico-científicos e à burocracia estatal da época: tratava-se, por um lado, de naturalistas, botânicos, jornalistas, escritores e políticos; por outro, de agentes que exerciam funções públicas ou burocráticas na administração estatal ou cuja atuação em associações ambientalistas estava estreitamente vinculada à ocupação de cargos em agências estatais (Urban, 2001). Nesse sentido, o movimento conservacionista desse período foi caracterizado como restrito a uma "elite de naturalistas" (Pádua, 1990). Um exemplo bem ilustrativo foi a criação da Fundação Brasileira para Conservação da Natureza - FBNC, em 1958, no Rio de Janeiro. Inspirada em associações de ativistas londrinos, era formada basicamente por cientistas naturais que desenvolviam estudos sobre espécies ameaçadas e também por jornalistas e políticos da época, transformando-se em uma entidade de atuação destacada tanto no âmbito nacional quanto no interna- 
cional entre 1950 e 1960 (Urban, 2001). Durante o governo Jânio Quadros, um de seus fundadores e também presidente do Conselho Florestal Federal, a FBNC participou na elaboração de medidas governamentais destinadas à proteção da natureza, na criação de áreas protegidas e na elaboração do Código Florestal de 1965. Tal associação também influenciou e apoiou grande parte das associações que surgiram no Brasil no início da década de 1970, desempenhando um importante papel na articulação do movimento conservacionista brasileiro com organizações e grupos internacionais.

Do mesmo modo, as mobilizações ambientalistas e as principais organizações que foram criadas no início da década de 1970 estavam voltadas para problemáticas relativamente antigas, algumas das quais remontam ao final do século XIX. Além disso, observa-se também certa continuidade entre esse "novo momento" do ambientalismo e o momento anterior, no sentido de que foram indivíduos vinculados às elites os fundadores e as lideranças das principais associações e mobilizações nos anos 1970 (ibidem). No entanto, esse momento se caracteriza também pela modificação das reivindicações e do potencial de mobilização em defesa de causas ambientais. Nesse sentido, a década de 1970 constitui um marco importante do processo de configuração do ambientalismo no Brasil como uma esfera de politização de diferentes espaços sociais. Segundo Loureiro e Pacheco (1995), é somente nos anos 1970 que a questão ambiental emerge como uma "questão política" no Brasil, pois é a partir daí que ela passa a ser integrada na "agenda dos problemas nacionais" e os problemas ambientais começam a "ocupar espaço crescente nos meios de comunicação e na opinião pública, mobilizando grupos em torno da defesa ambiental e formando o que se pode denominar de consciência ambiental no país" (ibidem:138). Para os militantes que participaram das mobilizações desse período, trata-se de um "novo começo" na medida em que os tipos de reivindicação que são levantados e as formas de intervenção utilizadas pelas organizações e dirigentes já não correspondem ao que ocorria anteriormente, durante a fase "conservacionista" ou "preservacionista" (Oliveira, 2005). Para eles, o "ecologismo" se caracteriza pelo questionamento da forma de "organização da sociedade", pois era o "modelo de civilização" que provocava a destruição da natureza ou de parte dela, de modo que somente uma "mudança global nas estruturas econômicas, sociais e culturais" da civilização poderia solucionar a "crise ambiental" (Mafra, 1995). Esse período é caracterizado também por "novos" repertórios de ação, que incluíam ações coletivas de denúncia e 
de mobilização da opinião pública, organização de manifestações de rua e de campanhas de politização de diversos temas. Um bom exemplo é a criação da Associação Gaúcha de Proteção ao Ambiente Natural - Agapan, em 1971, em Porto Alegre, constituindo o principal marco dessa "nova era" do movimento ambientalista brasileiro. Foi fundada por um grupo de profissionais liberais, como médicos, arquitetos, advogados, agrônomos, entre outros. Diferenciando-se do pensamento "conservacionista" existente até então, a entidade criticava as características assumidas pela civilização urbano-industrial e tinha entre suas principais reivindicações o combate à poluição do ar e da água e ao uso indiscriminado de agrotóxicos, visando à difusão de uma "nova moral ecológica". Tinha um estilo de atuação que, "inspirado nos movimentos ambientalistas surgidos nos EUA e na Europa nos anos 60, pautava-se pelo ativismo militante e pelo incentivo à mobilização cidadã, assumindo um caráter de vanguarda no ambiente repressivo que caracterizou a ditadura militar no Brasil" (Schmitt, 1995:87).

Todavia, diferentemente do que ocorria nos Estados Unidos e na Europa, tratava-se de mobilizações realizadas em um contexto político nacional ainda marcado pela existência de um "regime autoritário" em vigor desde a segunda metade da década de 1960 e que se caracterizou, entre outras razões, pela limitação formal das possibilidades de participação política. Várias organizações políticas que lutaram contra o golpe militar, como o movimento estudantil e certos grupos de esquerda, haviam sido perseguidas e proibidas de se manifestar, ao passo que muitas lideranças saíram do país e passaram a viver no exílio até meados dos anos 1980 (Landim, 2002). Já na esfera internacional, em decorrência das mobilizações desenvolvidas nos anos 1960 na Europa e nos Estados Unidos, voltadas para a promoção de um "espaço internacional" de expressão e de reivindicação (Ollitrault, 1999), encontra-se um cenário no qual a problemática ambiental emerge como um "discurso sem opositores", como uma dessas "causas generosas que suscitam $a$ priori a simpatia e que nenhum ator tem o interesse em colocar em causa" (Juhem, 2001:10), destacando-se como um dos marcos principais do período a realização, em 1972, da Conferência de Estocolmo, na Suíça. Nesse sentido, o fato de o discurso ambientalista, na situação em pauta, não se apresentar como uma contestação política ao "regime autoritário" vigente no Brasil constitui, certamente, um dos aspectos que contribuiu para o sucesso inicial das mobilizações levadas adiante pelos "fundadores" das primeiras organizações ambientalistas. Como bem salienta uma das lideranças do período em depoimento a Dreyer 
(2004:192): "Não éramos vistos como uma ameaça direta, como subversivos. Nosso discurso era político, mas era um conteúdo difícil de decifrar. Não estávamos falando contra o regime, falávamos contra todo um modelo". Todavia, mesmo que a ecologia tenha surgido nesse momento como uma espécie de "causa consensual" constituída por interesses e reivindicações que dizem respeito à "humanidade como um todo" (Agrikoliansky, 2002), trata-se de um discurso cujos "constrangimentos gramaticais particulares", como salienta Juhem (2001:26) a propósito do discurso humanitário, estão estreitamente vinculados às propriedades dos atores que o enunciam. Quanto a isso, cabe observar que as lideranças das principais associações e mobilizações ambientalistas constituídas no início da década 1970 reuniam algumas propriedades que resultavam de sua inserção simultânea no espaço internacional e nos espaços nacional e local.

A origem social elevada aparece, primeiramente, como uma das características principais do recrutamento e da seleção aos postos dirigentes nas organizações ambientalistas no início da década de 1970. A maioria dos dirigentes das primeiras associações são filhos de grandes comerciantes, de estancieiros, de juízes, de profissionais liberais, como advogados e engenheiros, e de oficiais militares com formação universitária. Trata-se de indivíduos, como bem definiu um desses dirigentes, que tiveram "toda a formação da boa sociedade", "boas escolas", formação superior. Suas famílias "viviam no mesmo meio", sendo que muitos deles já se conheciam antes de aderirem à causa ambiental em função dessa convivência comum, por freqüentarem os mesmos clubes e pelos laços de vizinhança ou de amizade há muito estabelecidos entre eles. $\mathrm{O}$ fato de se tratar de lideranças recrutadas em famílias de posição elevada e vinculadas às elites dirigentes do "regime autoritário" era uma das condições que possibilitava a redução dos custos que a participação em mobilizações políticas poderia acarretar para os indivíduos nesse período. A posição social de origem dos ambientalistas "fundadores" foi um dos fatores que possibilitaram seu engajamento na medida em que expunha tais indivíduos a um conjunto de situações e de experiências que contribuíram para a formação de certas disposições ligadas à participação na defesa de causas ambientais naquele momento. Os vínculos de parentesco e de amizade com o universo das elites política, religiosa, militar e empresarial é um dos principais ingredientes da socialização familiar de tais lideranças e constitui um dos fatores que estão na origem das disposições políticas que os conduziram à defesa de causas ambientais. Além disso, a origem estran- 
geira do grupo familiar, as viagens e os contatos freqüentes com organizações e pessoas em outros países estão na origem de seu cosmopolitismo e de suas propensões para aderir a problemáticas políticas e ideológicas que estão acima das divisões e das fronteiras nacionais (Loureiro e Pacheco, 1995:149). Junte-se a isso o fato de os tipos de engajamento que antecedem seu ingresso no ambientalismo consistirem na freqüência a clubes e a eventos culturais, a grupos naturistas e a organizações assistencialistas.

Tais aspectos estão na origem de um padrão de participação no ambientalismo baseado fundamentalmente na bagagem cultural e política herdada do grupo familiar de origem e resulta em uma concepção de participação política fundada nas relações estabelecidas a partir da esfera familiar. Trata-se de modalidades de inserção e de concepções de política "particularística" e "aristocrática" (Coradini, 1998), fundadas no "dom" e na "opinião pessoal" que decorrem de sua elevada condição social (Bourdieu, 1979), e não de formas de participação que pressupõem a aquisição de recursos militantes mediante filiação ou militantismo anterior em organizações políticas, partidárias e "movimentos sociais". Quando isso ocorre, os recursos militantes adquiridos mediante a participação em associações ambientalistas representam um "fim suplementar" que lhes permite "maximizar outros bens raros" que tais dirigentes possuem (Gaxie e Offerlé, 1985:111). Isso conduz a concepções e a práticas que remetem sua atuação na área de meio ambiente às esferas da "ética", da "filosofia" e dos "valores morais".

A maioria dos dirigentes iniciou sua participação em associações ambientalistas já com faixa etária elevada, em uma fase mais tardia da formação universitária e profissional e em um período próximo ao momento da aposentadoria. Mesmo assim, pode-se falar de um militantismo de reconversão profissional na medida em que tal engajamento está diretamente associado tanto à retomada quanto à reorientação da carreira e do exercício profissional. Nesse sentido, a participação em mobilizações e em organizações ambientalistas constitui uma forma de aquisição de posições de notabilidade com base na bagagem cultural e familiar mesmo para aqueles que não exerciam atividades profissionais ou que tiveram de recusá-las em decorrência da vida familiar. Pode-se, portanto, distinguir duas modalidades principais de adesão ao ambientalismo entre os dirigentes: de um lado aqueles casos cujo engajamento constitui uma forma de retomada de uma "carreira pro- 
fissional" interrompida; de outro, os que buscam, na defesa ambiental, uma maneira de reorientação de seu exercício profissional.

Em primeiro lugar, trata-se de modalidades de carreira de ambientalista constituídas por mulheres de empresários, médicos e juízes que haviam abandonado suas atividades e carreiras profissionais em função do casamento e da criação dos filhos. Dotadas de uma elevada bagagem cultural e escolar, no sentido que Saint-Martin (1999) chama de capital de "boa educação", elas adquiriram o aprendizado do voluntariado na família e na escola e, muito antes de atuarem no ambientalismo, apresentavam um itinerário de dedicação a atividades voluntárias, religiosas e caridosas. É como desdobramento da formação adquirida no meio familiar e escolar e desenvolvida por intermédio do trabalho voluntário que ocorre o ingresso na defesa do meio ambiente. Nesses casos, a atuação no trabalho voluntário e, posteriormente, no ambientalismo possibilita a "recuperação" ou a "retomada" de uma carreira escolar e profissional interrompida ou mesmo abandonada. Em decorrência da grande disponibilidade de tempo gerada pela ausência da necessidade de trabalhar, puderam se dedicar integralmente à organização, tornando-se verdadeiras "funcionárias" em um momento em que, segundo elas próprias, a "ecologia" não era algo "muitíssimo sério", como o é atualmente, pois consistia basicamente em uma "ocupação para pessoas que tinham tempo a dedicar". Com base nessas condições e nos recursos proporcionados pela família de origem, elas adquiriram notoriedade tanto no âmbito nacional quanto no internacional, conseguindo estabelecer parcerias e vínculos financeiros com empresas, organizações estatais, bem como com fundações e organismos internacionais.

Pode-se citar como trajeto típico dessa modalidade de carreira de ambientalista o caso da presidente de honra da Associação Democrática Feminina Gaúcha/Amigos da Terra - ADFG/AT. Seu pai era alemão e trabalhava como comerciante de importação, conseguindo dar continuidade a seu trabalho durante a guerra por causa das "ótimas amizades", sobretudo das relações de amizade estabelecidas com o dono do principal jornal do Rio Grande do Sul, Breno Caldas. Ela ingressou na associação quando estava com 40 anos, era casada com um grande empresário gaúcho, tinha três filhos e já havia concluído fazia bastante tempo sua formação universitária: tem mestrado no curso de línguas anglo-germânicas, sendo também formada em didática pela Faculdade de Filosofia da Universidade Federal do Rio Grande do Sul - 
UFRGS e em língua e literatura francesa pela Aliança Francesa de Porto Alegre. Primeiramente teve de interromper os estudos recusando, em decorrência da proibição do pai, uma bolsa para estudar um ano nos Estados Unidos; posteriormente, em função do casamento e da criação dos filhos. Antes mesmo de ingressar na entidade, já fazia o que chamou de "intervenção social", que consistia em fazer "bordadinhos" e doá-los à Igreja para "ajudar os pobres". Na referida associação, seu trabalho esteve inicialmente voltado para a "ação social": participação em cursos de assistência social na própria organização, em clube de mães, colégios, creches. Entretanto, foi quando o trabalho da associação se voltou para a temática ambiental que ela pôde retomar seus anseios antigos de atuação no âmbito internacional e, com base em uma grande disponibilidade profissional e, sobretudo, na notoriedade e no prestígio decorrentes dos vínculos familiares, conseguir a articulação do trabalho desenvolvido pela associação com organizações ambientalistas, organismos e fundações nacionais e internacionais. Desse modo, torna-se uma das principais articuladoras da aproximação entre a ADFG e as mobilizações ambientalistas e, mais tarde, da integração dessa organização à Federação Internacional Amigos da Terra.

Em segundo lugar, destacam-se as modalidades de atuação no ambientalismo representadas pelos que foram denominados "profissionais liberais". Diferentemente da modalidade anterior, trata-se de indivíduos que dispunham de uma razoável situação profissional e ocupacional como executivos de grandes empresas multinacionais (Basf, Citibank) ou como funcionários do setor público (Justiça Federal, universidade, Ministério da Agricultura). Seus engajamentos também ocorrem em uma faixa etária elevada, mas esta se combina com uma fase mais tardia do exercício da profissão, relativamente próxima ao momento de aposentadoria. Além da bagagem cultural propiciada por sua origem social elevada, esses dirigentes podiam contar também com a "notoriedade" e os vínculos estabelecidos por meio do exercício profissional. A adesão ao ambientalismo funciona como uma forma de reorientação de suas atividades e do próprio exercício da profissão. Em alguns casos, tal redefinição constitui uma forma de retomada de certas aspirações descartadas no decorrer de seus itinerários escolares e profissionais. Uma das características predominantes nesse conjunto é a articulação entre a bagagem cultural adquirida através da família de origem e certa "notabilidade" e prestígio vinculados à formação e ao exercício profissional como instrumento de intervenção em diferentes esferas de atuação. 
Um dos exemplos mais representativos dessa modalidade de atuação profissional é o caso do primeiro presidente da Agapan (ver Dreyer, 2004). Um dos principais aspectos que chama a atenção nesse caso e o torna extremamente significativo quanto às modalidades de reconversão profissional dos ambientalistas da década de 1970, e até mesmo dos dirigentes das gerações posteriores, é justamente a diversidade de esferas que por meio de sua atuação passa a ser vinculada à defesa ambiental. Essa combinação de atuação diversificada corresponde também a seu reconhecimento simultâneo para com um conjunto bastante heterogêneo de qualidades, tais como "cientista", "professor", "agrônomo", "ecologista".

Ele era filho de um arquiteto bem-sucedido, que se tornou mais tarde pintor e professor do Instituto de Belas Artes da UFRGS, e de uma "fervorosa liderança da comunidade católica" que pertencia a uma das famílias de maior influência política e econômica no Rio Grande do Sul. Formou-se em agronomia pela UFRGS e, logo em seguida, conseguiu uma bolsa de estudos na Louisiana State University, nos Estados Unidos, onde realizou um curso de pós-graduação em estudos do solo e agroquímica. Após trabalhar durante sete anos na Companhia Riograndense de Adubos e, depois, na Sulpampa, do mesmo ramo, foi contratado para trabalhar com fertilizantes como um alto executivo da multinacional Basf, que era também a empresa para a qual trabalhava seu sogro. Em função desse novo emprego, ficou fora do país como executivo da empresa durante treze anos: dois na Alemanha, sete na Venezuela e quatro no Marrocos.

Seu ingresso no ambientalismo ocorreu quando estava com 45 anos e tem como marco seu pedido de demissão da Basf, segundo ele próprio, para "mudar o rumo da minha vida". Quando isso ocorreu, ele já havia aderido ao naturismo, estabelecido contato com algumas associações e lideranças vinculadas ao "ecologismo" na Europa e nos Estados Unidos, chegando a entrar em contato com algumas "entidades de luta", como ele mesmo definiu, que eram a Audubon Society ou o Sierra Club, as quais o inspirou na criação da Agapan. Sua "experiência internacional" foi decisiva para a ocupação do cargo de presidente dessa associação (Urban, 2001). A partir daí, entrega-se totalmente ao "trabalho de proteção ambiental", a ponto de se tornar um "ativista em tempo integral". Com base na visibilidade, na projeção e nos vínculos alcançados nos âmbitos nacional e internacional, consegue articular de maneira exemplar e duradoura o ativismo ambiental com a atuação profissional em associações ambientalistas, organizações profissio- 
nais, empresas, administrações e organismos públicos nas áreas de manejo e reciclagem de resíduos, paisagismo, urbanismo, saneamento natural (Dreyer, 2004).

A principal característica da participação na defesa de causas ambientais no Brasil a partir da década de 1970 é a mudança de uma situação em que a temática ambiental estava restrita a uma "elite de naturalistas" - no sentido de que se tratava de indivíduos vinculados predominantemente aos setores técnico-científicos e à burocracia estatal - para uma outra, que trata de indivíduos pertencentes às elites econômica, política, cultural, militar e religiosa e que atuam como "ambientalistas" em diferentes setores da sociedade. Nesse sentido, pode-se falar da década de 1970 como um marco do processo de constituição da defesa ambiental como um espaço de articulação de recursos diversificados para a politização e a intervenção em diferentes esferas de atividade. Todavia, até o final dos anos 1970, as bandeiras de luta do ambientalismo ainda eram levadas a cabo por um número relativamente pequeno de organizações e diziam respeito a reivindicações pontuais e específicas, como a poluição do ar e da água, provocada pela Borregaard Celulose; o uso abusivo de agrotóxicos; a luta contra a instalação do Pólo Petroquímico; e a denúncia contra a destruição de reservas florestais e espécies em extinção (Tornquist, 1992; Schmitt, 1995).

Como se pode perceber pelos dados apresentados, os recursos que respaldam o ingresso e a permanência na defesa ambiental naquele contexto político se encontram estreitamente associados à bagagem cultural e aos vínculos sociais e políticos adquiridos a partir da família de origem. São os indivíduos pertencentes às famílias que mantêm laços estreitos com as elites governantes os que assumem as posições de liderança das principais associações e mobilizações existentes naquele momento. Associado a isso, observa-se que as causas defendidas pelas organizações e pelos dirigentes ambientalistas estavam situadas acima das divisões políticas e ideológicas que agitavam o cenário político nacional e internacional naquele momento, não constituindo uma "questão política" que ameaçasse ou desafiasse o sistema político vigente. É somente a partir da chamada "abertura política" que a composição social das organizações ambientalistas sofre uma grande modificação. A imensa proliferação de organizações e de "movimentos sociais" se torna um dos ingredientes principais da diversificação da composição social das organizações ambientalistas e das estruturas or- 
ganizacionais e ideológicas do ambientalismo brasileiro, de modo que o recrutamento das principais lideranças passa a se concentrar nessas redes de organização e de "movimento social" vinculadas à luta pela "democratização" (Alonso, Costa e Maciel, 2007). Dessa forma, pode-se observar uma forte correspondência entre um contexto de "abertura política" e de intensa luta pela "democratização" e uma maior imbricação entre as reivindicações dos ambientalistas e os objetivos e bandeiras de lutas defendidas pelos grupos e organizações vinculados às problemáticas social, popular e partidária.

\section{"REDEMOCRATIZAÇÃO", MILITÂNCIA MÚLTIPLA E ATUAÇÃO PROFISSIONAL}

A partir da segunda metade da década de 1980, observa-se um aumento expressivo do número de organizações e de participantes nas mobilizações em defesa de causas ambientais, bem como uma maior diversificação dos tipos de reivindicação e de bandeira de luta que passaram a integrar a atuação das organizações e lideranças ambientalistas (Schmitt, 1995). Nesse sentido, pode-se falar da década de 1980 como o marco da "explosão" do número de associações ambientalistas brasileiras. No caso do Rio Grande do Sul, observa-se que, do total de associações existentes entre 1970 e 2004, apenas 18\% foram criadas nos anos 1970 , ao passo que um percentual de $82 \%$ corresponde às que surgiram entre os anos 1980 e o início dos anos 2000. Tomando-se como referência as mobilizações ocorridas na década anterior, pode-se dizer que nos anos 1980 se assiste ao surgimento de uma "segunda geração" de organizações e de lideranças ambientalistas. Nesse sentido, alguns trabalhos vão afirmar que é somente nesse período que se pode falar propriamente de "movimento ecológico", pois é a partir daí que ocorre a articulação dos mais diferentes grupos e organizações sociais com as lutas ambientais.

Algumas das principais lutas desenvolvidas pelas organizações ambientalistas do Rio Grande do Sul têm como referência esse período, como é o caso da aprovação da Lei Estadual de Agrotóxicos, em 1983, cuja elaboração contou com a articulação de diversos tipos de organização social, o que resultou na participação de aproximadamente cem entidades. Foi também no início dos anos 1980 que ocorreu a luta contra a instalação do II Pólo Petroquímico, próximo a Porto Alegre, à beira da Lagoa dos Patos. Os protestos contra o governo do Estado, que era favorável a tal instalação, foram marcados pela crítica tanto aos da- 
nos ambientais quanto à forma como a decisão foi tomada. Esses protestos contaram também com o apoio e a participação de diversas organizações que não eram vinculadas às lutas ambientalistas, como entidades profissionais e comunitárias, além de políticos de oposição. A mobilização se caracterizou pela inauguração de novas formas de fazer protesto - realização de shows, seminários, acampamentos à beira da Lagoa dos Patos, divulgação de cartilhas - e pela manutenção de um intenso debate na imprensa acerca do projeto. A luta contra a instalação do Pólo Petroquímico é reconhecida como um marco na história do ambientalismo gaúcho. Foi por meio dela que o "pensamento ecologista" encontrou uma importante divulgação no "seio da sociedade gaúcha" (Tornquist, 1992). Assim, como salienta Schmitt (1995:87), essa luta trouxe

importantes avanços políticos e organizativos para o movimento, divulgando a problemática ambiental junto à população, motivando a formação de novas entidades de "defesa do meio ambiente", fomentando alianças entre os grupos ecológicos e as demais organizações da sociedade civil e forçando o Governo do Estado a reconhecer os "verdes" como interlocutores legítimos.

Com isso, militantes vinculados às lutas estudantis passam a integrar as organizações de mobilização em defesa de causas ambientais, dando origem a novas associações ambientalistas. Esse é o caso do grupo Em Nome do Amor à Natureza, formado por universitários militantes do movimento estudantil que eram contrários à centralização e ao "apartidarismo" da Agapan. Em função disso, adotavam "procedimentos democráticos", como a organização de forma descentralizada e horizontal, definiam-se como uma organização "eminentemente política" e propunham a ligação entre as questões ambientais e as problemáticas sociais e políticas mais amplas. Outro grupo, Deite na Grama, também constituído por estudantes universitários, caracterizou-se pela proposta de "ecologização dos estudantes em geral", no sentido de que a universidade adotasse a "perspectiva ecológica" em seus cursos e em suas práticas cotidianas. Por fim, um bom exemplo da maior aproximação e da influência decisiva da política partidária sobre as organizações e as reivindicações ambientalistas do Rio Grande do Sul nesse período é a criação do Núcleo de Ecologistas do Partido dos Trabalhadores - PT, em 1985, a partir da iniciativa de dirigentes das principais associações ambientalistas que também faziam parte do referido partido. Esse núcleo tinha como objetivo principal reunir os "ecologistas 
petistas" que atuavam em diferentes entidades e propor uma intervenção organizada no "movimento ecológico gaúcho" (Tornquist, 1992). Além do surgimento dessas e de outras entidades e da vinculação de organizações as mais diversas em torno de lutas comuns, foi também nesse período que as organizações ambientalistas começaram a se articular com partidos políticos para apoiar as candidaturas de lideranças comprometidas com a causa ambiental (Schmitt, 1995). Isso ocorreu durante a campanha pelas Diretas, nas eleições de 1986 para a Constituinte, com a elaboração de "listas verdes" na formulação de uma proposta de governo intitulada Proposta de Vida para Porto Alegre, que foi entregue para todos os candidatos às eleições municipais, assim como na eleição de dois "vereadores ecologistas" pelo PT, em 1988, que faziam parte da diretoria da Agapan e eram também do Núcleo de Ecologistas do PT. Trata-se, portanto, de um período no qual ocorre uma forte imbricação entre "lutas ambientais" e "sociais", que se manifesta sobretudo pela maior aproximação entre associações ambientalistas, sindicatos, ONGs "sociais" e grupos herdeiros dos movimentos populares da década de 1970, bem como pela incorporação de forma generalizada de debates e reivindicações ambientais pelos setores empresariais, órgãos jurídicos, agências governamentais, partidos políticos, universidades e centros de pesquisa (Loureiro e Pacheco, 1995).

Entre os fatores que estão na origem dessas mudanças nas condições e nas formas de protesto ambiental se encontram, inicialmente, certas transformações ocorridas nas estruturas de oportunidades políticas vinculadas ao chamado processo de redemocratização. Trata-se de um contexto político em que o Brasil estava iniciando um longo processo de "abertura política" em relação ao regime autoritário e que se caracteriza por uma grande afluência de organizações, grupos e lideranças dos mais diversos setores sociais que se mobilizam contra a ditadura por meio de manifestações de rua pela "democratização" (Linz e Stepan, 1999). A partir da segunda metade dos anos 1970, as possibilidades de mobilização do ativismo ambientalista se expandiram acentuadamente, em decorrência de modificações nas "dimensões formais e informais do ambiente político" relacionadas à chamada "abertura política" (Alonso, Costa e Maciel, 2007:4). Trata-se, mais especificamente, da diminuição da repressão aos protestos sociais em geral; da maior permeabilidade das instituições políticas e administrativas às reivindicações da "sociedade civil"; da diversificação de lideranças e movimentos sociais com o fim do bipartidarismo; da constituição de redes 
de aliança entre lideranças da Igreja Católica, da Ordem dos Advogados do Brasil - OAB, da mídia, dos partidos políticos, das elites dissidentes e dos diversos movimentos sociais; da constituição de uma agenda ambientalista internacional após a Conferência de Estocolmo.

Esse contexto foi marcado também por transformações no espaço de formação escolar e profissional decorrentes da expansão e da diversificação do ensino superior. Todavia, muito mais do que uma simples expansão formal, há sobretudo uma acentuada diversificação das redes sociais vinculadas à formação universitária (Coradini, 2002). Como demonstra Mische (1997:144), durante esse período, a maioria dos estudantes universitários é socializada, com mais freqüência, "fora da escola", por meio de redes diversificadas de estudo, trabalho e sociabilidade. Associado a isso, assiste-se a uma ampliação das formas de participação social e política dos estudantes universitários em redes diversificadas de movimentos, partidos e outras organizações que se cruzam nas mobilizações pela "redemocratização". Esse maior entrelaçamento de organizações diversificadas durante o processo de redemocratização favoreceu o surgimento de redes de liderança de diferentes organizações e movimentos sociais extremamente interligadas e intensificou o "fenômeno da militância múltipla" (Mische, 1997). Sendo assim, a inserção e a militância anterior e/ou simultânea em múltiplas redes de organização e de movimento social constituem um dos principais recursos para a ampliação dos usos instrumentais da escolarização e da formação profissional com vistas à politização e à articulação de diferentes esferas de atuação (Coradini, 2002; Pécaut, 1990).

Esse conjunto de mudanças na estrutura de oportunidades políticas, propiciadas pelo processo de redemocratização, e sua vinculação com a diversificação do ensino universitário contribuíram para a modificação do perfil dos ativistas das associações ambientalistas na medida em que influenciaram a transformação das próprias bases sociais e das dinâmicas de ingresso e de permanência em tal militantismo. Nesse sentido, observa-se que, diferentemente do que ocorria na geração anterior, o momento de ingresso no ambientalismo a partir dos anos 1980 coincide com o início da formação universitária e com o processo de entrada no mercado de trabalho. Essa associação do engajamento político com a formação universitária e profissional não ocorre apenas no momento de adesão ao ambientalismo ou no momento posterior à entrada nas organizações ambientalistas. Pelo contrário, a inserção ante- 
rior ou simultânea em diversas redes de organização e de "movimento social" constitui um dos condicionantes principais do ingresso, da permanência e da ocupação de postos nas organizações e instâncias que atuam na defesa de causas ambientais (Oliveira, 2007).

Com isso, ampliaram-se consideravelmente as possibilidades de articulação da formação escolar e universitária com diversas esferas de atuação, por meio do engajamento na defesa de causas ambientais. Desse modo, paralelamente à diversificação das organizações, dos atores e das reivindicações vinculadas à defesa de causas ambientais, observa-se uma ampliação das associações, lideranças e "facções" do movimento ambientalista cujas bandeiras de luta e intervenções estão articuladas ao militantismo em grupos estudantis, sindicatos e associações profissionais, em partidos políticos, em organizações religiosas ou em outras organizações e movimentos populares, assim como em empresas de consultoria, em administrações públicas e na burocracia estatal. Com o surgimento de novas possibilidades de articulação da formação escolar e profissional com diversas esferas de atuação por meio da defesa ambiental, houve um crescimento considerável do potencial de retribuição da participação na defesa do meio ambiente a partir desse período. Isso porque esse tipo de engajamento passou a ser associado à ocupação de postos nas administrações públicas e na burocracia estatal, nos partidos políticos, nos meios acadêmicos e universitários, em organizações e grupos profissionais, em empresas de consultoria, entre outras. Sendo assim, na medida em que os postos profissionais ocupados com base na participação de organizações ambientalistas estão fundados em recursos e vínculos estabelecidos pela inserção anterior ou simultânea das lideranças em organizações e movimentos sociais variados e no maior entrelaçamento entre as redes de liderança que atuam nessas diversas esferas de atividade, as retribuições obtidas pelo militantismo ambientalista se tornaram extremamente diversificadas.

Tais aspectos estão na origem de um padrão de participação no ambientalismo bem diferenciado daquele encontrado no período anterior. Trata-se agora de indivíduos com origens sociais mais baixas e heterogêneas, que têm como principal base de recursos as inserções e os vínculos estabelecidos no decorrer de seus itinerários familiar, escolar e profissional com organizações e "movimentos sociais" diversificados (estudantis, sindicais, partidários, religiosos), e cujas concepções de participação política remetem à politização das mais diferentes esferas 
de atividade com base nesse intenso militantismo (idem, no prelo). Todavia, no que tange à diversidade de esferas sociais associadas à atuação profissional na defesa de causas ambientais, podem-se identificar certas regularidades em termos dos vínculos sociais e políticos que estão na base de tal forma de exercício profissional.

Uma modalidade de adesão típica dessas novas condições históricas e sociais é constituída pelos casos em que a atuação em diferentes esferas de atividade (organizações ambientalistas, conselhos e secretarias de proteção ambiental, administrações públicas) tem como base de recurso principal as inserções e os vínculos anteriores e/ou simultâneos estabelecidos com organizações partidárias. Um trajeto exemplar dessa modalidade de carreira de ambientalista é o caso do dirigente da associação HocTempore, de Pelotas, que se caracteriza pelo intenso militantismo em organizações estudantis e partidárias e pela articulação do engajamento associativo com a ocupação de cargos e funções remuneradas na administração pública e na burocracia estatal com base nos vínculos estabelecidos na militância partidária. Ele tem 34 anos, é filho único e natural de Herval, onde o pai trabalha com comércio de carros e a mãe é professora do ensino fundamental. Durante o segundo grau, deslocou-se para a cidade de Pelotas, formando-se em eletromecânica pela Escola Técnica e em direito pela Universidade Federal de Pelotas UFPel. Seus pais eram adeptos do Partido Democrático Trabalhista PDT, mas ele iniciou sua participação política por meio do grêmio estudantil e, depois, pela militância no PT, integrando a "tendência" chamada de "democracia socialista".

Como ele mesmo salienta, foi a "participação político-partidária" que o conduziu ao "movimento ambiental", no sentido de que foi com base na "aproximação ideológica" com ambientalistas do Centro de Estudos Ambientais - CEA, também filiados ao PT, que decidiu integrar tal associação. Desse modo, durante a formação universitária, ocupou posição de direção no Diretório Central de Estudantes, no CEA, além de participar da "setorial de meio ambiente" do PT no âmbito estadual. Foi com base nesse trajeto de militância simultânea no PT e no CEA que ocupou a pasta de secretário municipal de Qualidade Ambiental durante a administração petista no município de Pelotas (2001-2004). Todavia, no decorrer do processo de sucessão do então prefeito e candidato à reeleição, tomou uma posição favorável à sua reeleição, contrariando a decisão de outras lideranças do CEA, que, em função de atritos com o então prefeito, decidiram indicar outro candidato petista. 
Com isso, desligou-se da associação, criou uma outra denominada HocTempore e, com base nos vínculos de longa data estabelecidos no PT, assumiu um cargo no Ministério do Meio Ambiente. Atualmente é um dos principais articuladores de uma rede de ONGs voltadas para a defesa do Bioma Pampa, a qual já conta com a adesão de aproximadamente oitenta associações ambientalistas do Rio Grande do Sul. Disso resulta uma concepção do movimento ambientalista como devendo estar associado à política partidária. Ou seja, a única forma de unificar os objetivos e estratégias de luta das organizações e mobilizações ambientalistas é, necessariamente, por meio de uma orientação comum para a intervenção no âmbito da política partidária. O que fundamenta essa imbricação da "política ambiental" com a "partidária" é uma concepção militantista da própria política partidária, no sentido de que esta deve estar sempre associada com outras esferas de militância (Coradini, 2002).

Em outro extremo, encontram-se modalidades de atuação que têm como base de recurso principal os vínculos estabelecidos a partir da esfera universitária. Nesses casos, são as relações constituídas a partir da universidade com lideranças que atuam em diferentes esferas de atividade - universidades, associações ambientalistas, burocracia estatal, movimentos sociais - que possibilitam a reconversão da formação escolar para a atuação em tais esferas. Um dos casos exemplares é a coordenadora técnica da ADFG/AT, que tem um trajeto de forte imbricação da formação universitária com a militância ambientalista, inicialmente por meio do próprio movimento estudantil, seguido da ocupação de funções técnicas em agências estatais e da inserção em organizações e movimentos sociais na esfera internacional. Trata-se de uma geóloga, natural de Porto Alegre, com 38 anos e casada com um ex-colega de faculdade. Seu pai é um engenheiro mecânico que ocupava cargos de administração na indústria automobilística e a mãe uma professora que abandonou o ensino em decorrência do nascimento dos filhos. Seus pais não participavam de organizações políticas ou movimentos sociais. Foi através do universo escolar e universitário que ela desenvolveu o gosto pela participação associativa. Isso ocorreu, primeiramente, pela atuação em diretórios e encontros de estudantes do curso de geologia em questões vinculadas à temática ambiental. Em função disso, direcionou o mestrado para a área de meio ambiente, começando a participar da ADFG por meio de um colega de curso que era vice-presidente da associação e desenvolvia um projeto em parceria com a universidade. Daí centrou sua pesquisa na questão da "poluição 
causada por metais pesados" e na "avaliação do impacto disso na saúde humana". No final do mestrado, atuou como estagiária na Fundação Estadual de Proteção Ambiental Henrique Luiz Roessler - Fepam, vinculada à Secretaria Estadual de Meio Ambiente do Rio Grande do Sul - Sema-RS, em um projeto sobre a "poluição do carvão", sendo depois indicada por seu orientador para fazer um curso na Alemanha. Já no curso, sentiu-se mais impulsionada a participar da associação. Entrou em contato com a Federação Amigos da Terra Internacional e percebeu que podia, dentro da ADFG/AT, fazer de seu trabalho "um trabalho profissional e que existiam fontes de financiamento e de projeto, inclusive dos Amigos da Terra Internacional". Sendo assim, ao retornar, abandonou o estágio na Fepam em troca de uma função remunerada na ADFG/AT e depois ainda na Rios Vivos. Também nesse caso, a utilidade do conhecimento técnico-científico está diretamente associada ao militantismo em organizações e movimentos sociais diversificados. Mesmo que sua intervenção na associação esteja centrada no exercício de uma função técnica vinculada ao tema "energia", trata-se da realização de uma função de articuladora da ADFG/AT com "redes associativas" e organizações nacionais e internacionais. Nesse sentido, ela salienta que uma maneira de "trabalhar e fortalecer o movimento" não é "nem estudando ou levando especificamente um tema", mas sim possibilitando os "contatos entre as pessoas", "botando uma entidade em contato com a outra".

\section{CONSIDERAÇÕES FINAIS}

Como este artigo buscou demonstrar, há uma relação muito forte entre as características do contexto político, as propriedades sociais dos ativistas e as dinâmicas de engajamento individual na defesa de causas coletivas. Nesse sentido, a reconstituição social da gênese e das transformações do ativismo ambiental nos mostra o peso diferenciado das condições de origem e das inserções em redes de organização e de movimento social para o ingresso e a permanência no ambientalismo nos diferentes contextos políticos considerados.

No contexto ditatorial e de restrição formal da participação política, eram indivíduos pertencentes ou que tinham acesso privilegiado aos grupos ou às elites governantes os principais protagonistas das lutas ambientais. Isso porque era indispensável reunir as condições e os recursos necessários para a realização de tal empreendimento, sem acarretar custos políticos e profissionais elevados a esses ativistas, de 
modo que eram os de origem social elevada e com vínculos estreitos com as elites econômica, militar, política e cultural os que detinham mais facilidades. Diferentemente, mesmo que não esgote o conjunto de recursos e esferas sociais associadas à participação no ambientalismo, os exemplos referentes ao contexto de "abertura política" e de "redemocratização" demonstram a grande importância dos recursos e vínculos decorrentes da inserção em organizações partidárias e em movimentos sociais diversificados para o ingresso e a continuidade em organizações ambientalistas a partir dos anos 1980. Em consonância com isso, observa-se uma mudança significativa na composição social das principais associações de proteção ambiental e, conseqüentemente, nos objetivos perseguidos com as mobilizações e em suas relações com outros tipos de organização política, bem como uma grande proliferação de organizações ambientalistas atuando nas mais diferentes esferas de atividade, com os mais diferenciados objetivos ideológicos e a partir das vinculações de seus dirigentes a redes de organização e de movimento social as mais variadas.

Dessa forma, ao contrário das abordagens que consideram a emergência e as transformações das mobilizações ambientalistas um resultado direto de um processo de "difusão internacional", de "universalização" e de "imposição" de causas legítimas, este artigo visou demonstrar a importância de integrar a análise das características e das modificações relacionadas à estrutura de oportunidades e aos processos políticos nos quais emergem as mobilizações coletivas à investigação dos tipos de recurso e de vínculo social e político que conduzem os indivíduos ao engajamento e à permanência no militantismo. Sendo assim, em vez de se considerarem as condições de origem e os recursos utilizados pelos ativistas como fatores constantes para o surgimento e o desenvolvimento das mobilizações coletivas, foram evidenciadas suas modificações no decorrer do tempo e seu peso relativo em diferentes contextos políticos.

Tal investigação demonstrou que a análise do contexto político em que se desenvolve determinada mobilização coletiva constitui um bom ponto de partida para uma pesquisa mais detalhada do grau variável de pertinência das condições sociais de origem e das redes de recrutamento para as dinâmicas do engajamento individual. A combinação entre as configurações do contexto político e os tipos de condição e de rede social vinculados à emergência e às dinâmicas de transformação das mobilizações ambientalistas constitui um dos aspectos principais para a apreensão das dinâmicas de reconversão profissional por meio 
da participação na defesa de causas ambientais na referida situação. É com base nisso que se pode melhor compreender os significados atribuídos à atuação profissional nesses diferentes momentos, bem como as principais modificações que ocorreram nas formas de definição e de intervenção dos ambientalistas.

(Recebido para publicação em agosto de 2007)

(Versão definitiva em junho de 2008)

\section{REFERÊNCIAS BIBLIOGRÁFICAS}

AGRIKOLIANSKY, Eric. (2002), La Ligue Française des Droits de L'Homme et du Citoyen Depuis 1945. Paris, L'Harmattan.

ALONSO, Angela e COSTA, Valeriano. (2002), "Ciências Sociais e Meio Ambiente no Brasil: Um Balanço Bibliográfico". BIB, no 53, pp. 35-78.

- e MACIEL, Débora Alves. (2007), “O Processo de Formação da Rede de Ativismo Ambientalista no Brasil". XIII Congresso Brasileiro de Sociologia. Recife, 29 de maio-6 de junho de 2007.

ANQUETIN, Virginie. (2002), “Produire une Politique Municipale de l’Environnement: La Régulation des Interactions des Acteurs Locaux par l'Expertise", in P. Hamman, J.-M. Méon e B. Verrier (orgs.), Discours Savants, Discours Militants: Mélange des Genres. Paris, L'Harmattan, pp. 129-151.

BONES, Elmar e HASSE, Geraldo. (2002), Pioneiros da Ecologia. Breve História do Movimento Ambientalista no Rio Grande do Sul. Porto Alegre, Já Editores.

BOURDIEU, Pierre. (1979), La Distinction. Critique Sociale du Jugement. Paris, Minuit.

CORADINI, Odaci Luiz. (1998), “Panteões, Iconoclastas e as Ciências Sociais", in L. O. Félix e C. P. Elmir (orgs.), Mitos e Heróis. Construção de Imaginários. Porto Alegre, Ed. Universidade/UFRGS, pp. 209-235.

. (2002), "Escolarização, Militantismo e Mecanismos de 'Participação' Política", in B. Heredia, C. Teixeira e I. Barreira (orgs.), Como se Fazem Eleições no Brasil. Rio de Janeiro, Relume Dumará, pp. 103-153.

DEVAUX, Sandrine. (2005a), Engagements Associatifs et Postcommunisme. Le Cas de la République Tchèque. Paris, Belin.

(2005b), Les Nouveaux Militantismes dans l'Europe Élargie. Paris, L'Harmattan.

DEZALAY, Yves e GARTH, Bryant. (2002), La Mondialisation des Guerres de Palais. La Restructuration du Pouvoir d'État en Amérique Latine, entre Notables du Droit et "Chicago Boys". Paris, Seuil. 
DREYER, Lilian. (2004), Sinfonia Inacabada. A Vida de José Lutzenberger. Porto Alegre, Vidicom Audiovisuais Edições.

FILLIEULE, Olivier. (2001), "Propositions pour une Analyse Processuelle de l'Engagement Individuel". Revue Française de Science Politique, vol. 51, nos 1-2, pp. 199-215.

GALLET, Gérald. (2002), “L’Expertise, Outil de l'Activisme Environnemental chez Greenpeace France", in P. Hamman, J.-M. Méon e B. Verrier (orgs.), Discours Savants, Discours Militants. Mélange des Genres. Paris, L'Harmattan, pp. 109-128.

GAXIE, Daniel e OFFERLÉ, Michel. (1985), “Les Militants Syndicaux et Associatifs au Pouvoir? Capital Social Collectif et Carrière Politique", in P. Birnbaum (org.), Les Élites Socialistes au Pouvoir. Les Dirigeants Socialistes Face à l'État, 1981-1985. Paris, PUF, pp. 105-138.

JUHEM, Philippe. (2001), “La Légitimation de la Cause Humanitaire: Un Discours sans Adversaires". Mots, no 65, pp. 9-27.

LANDIM, Leilah. (2002), “Experiência Militante. História das Assim Chamadas ONGs”. Lusotopie, no 1, pp. 215-239.

LINZ, Juan J. e STEPAN, Alfred. (1999), A Transição e Consolidação da Democracia. A Experiência do Sul da Europa e da América do Sul. São Paulo, Paz e Terra.

LOUREIRO, Maria Rita e PACHECO, Regina Silva. (1995), “Formação e Consolidação do Campo Ambiental no Brasil: Consensos e Disputas (1972-1992)". Revista de Administração Pública, vol. 29, no 4, pp. 137-153.

MAFRA, Humberto (org.). (1995), Desafios e Perspectivas do Movimento Ambientalista no Brasil. Brasília, Fundação Francisco.

MATHIEU, Lilian. (2002), “Rapport au Politique, Dimensions Cognitives et Perspectives Pragmatiques dans l'Analyse des Mouvements Sociaux". Revue Française de Science Politique, vol. 52, № 1, pp. 75-100.

MATONTI, Frédéric e POUPEAU, Franck. (2004), “Le Capital Militant. Essai de Définition". Actes de la Recherche en Sciences Sociales, no 155, pp. 5-11.

MCADAM, Doug, MCCARTHY, John D. e ZALD, Mayer N. (eds.). (1996), Comparative Perspectives on Social Movements. Political Opportunities, Mobilizing Structures, and Cultural Framings. Cambridge/New York, Cambridge University Press.

MISCHE, Ann. (1997), “De Estudantes a Cidadãos. Redes de Jovens e Participação Política". Revista Brasileira de Educação, nos 5-6, pp. 134-150.

OLIVEIRA, Wilson José Ferreira. (2005), "Paixão pela Natureza”, Atuação Profissional e Participação na Defesa de Causas Ambientais no Rio Grande do Sul entre 1970 e Início dos Anos 2000. Tese de doutorado em Antropologia Social, UFRGS, Porto Alegre. Disponível em http://www.bibliotecadigital.ufrgs.br/da.php?nrb=000526042\& loc $=2006 \& 1=$ bf2bb6bbdcf3022e, acessado em 27/5/2007.

. (2006), As Condições Sociais de Institucionalização de Perspectivas Teóricas no Estudo das Mobilizações Ambientalistas. Trabalho apresentado no III Encontro Anual da Associação Brasileira de Pesquisa e Pós-Graduação em Ambiente e Sociedade. Brasília, 23-26 de maio. Disponível em http://www.anppas.org.br/encontro _anual/encontro3/arquivos/TA274-07032006-195842.PDF, acessado em $27 / 5 / 2007$. 
(2007), “Formas Precárias de Emprego, Atuação em ONGs e Inserção Profissional". Sociedade em Debate, vol. 13, no 1, pp. 141-160.

. (no prelo), "Redes Sociais, Reconversão Profissional e Participação em Conselhos e Instâncias de Proteção Ambiental no Rio Grande do Sul". Teoria E Sociedade.

OLliTRAUlT, Sylvie. (1999), “De la Caméra à la Pétition-Web: Le Répertoire Médiatique des Écologistes". Réseaux, no 98, pp. 153-185.

. (2001), “Les Écologistes Français, des Experts em Action”. Revue Française de Science Politique, vol. 51, nos 1-2, pp. 105-130.

PÁDUA, José Augusto. (1990), “O Nascimento da Política Verde no Brasil: Fatores Exógenos e Endógenos". Ciências Sociais Hoje, 1990. São Paulo, Vértice/Revista dos Tribunais, pp. 190-216.

PASSY, Florence. (1998), L'Action Altruiste. Paris/Genève, Droz.

PÉCAUT, Daniel. (1990), Os Intelectuais e a Política no Brasil: Entre o Povo e a Nação. São Paulo, Ática.

ROOTES, Christopher (ed.). (1999), Environmental Movements: Local, National and Global. London, Frank Cass.

SAINT-MARTIN, Monique de. (1999), “Uma ‘Boa' Educação”. Educação \& Sociedade, ano XX, no 66, pp. 104-122.

SAINTENY, Guillaume. (1999), “Logiques d'Engagement et Logiques de Rétribution au Sein de l'Écologisme Français". Cahiers Internationaux de Sociologie, vol. CVI, pp. 175-200.

. (2000), L'Introuvable Écologisme Français? Paris, PUF.

SCHMITT, C. J. (1995), “Mata de Araucárias: A Região Norte do Rio Grande do Sul”, in I. C. de M. Carvalho e G. Scotto (coords.), Conflitos Sócio-Ambientais no Brasil. Rio de Janeiro, Graphos, pp. 25-101.

SIMÉANT, Johanna e DAUVIN, Pascal. (2002), Le Travail Humanitaire. Les Acteurs des ONG, du Siège au Terrain. Paris, Presses de Sciences Po.

SVIRSKY, Enrique e CAPOBIANCO, João Paulo (orgs.). (1997), Ambientalismo no Brasil: Passado, Presente e Futuro. São Paulo, Instituto Socioambiental, Secretaria do Meio Ambiente do Estado de São Paulo.

TARROW, Sidney. (1988), “National Politics and Collective Action: Recent Theory and Research in Western Europe and the United States". Annual Review of Sociology, vol. 14, pp. 421-440.

TONI, Fabiano. (2001), “Novos Rumos e Possibilidades para os Estudos dos Movimentos Sociais". BIB, no 52, pp. 79-104.

TORNQUIST, Carmen Susana. (1992), O Planeta e o Quintal: O Movimento Ecológico frente à Administração Popular em Porto Alegre. Dissertação de mestrado, UFSC, Florianópolis.

URBAN, Teresa. (2001), Missão (quase) Impossível. Aventuras e Desventuras do Movimento Ambientalista no Brasil. São Paulo, Peirópolis.

WAGNER, Anne-Catherine. (2004), “Syndicalistes Européens. Les Conditions Sociales et Institutionnelles de l'Internationalisation des Militants Syndicaux". Actes de la Recherche en Sciences Sociales, no 155, pp. 13-34. 


\section{ABSTRACT}

The Birth and Redefinitions of Environmental Activism in Brazil

This article examines the conditions under which environmental activism emerged and evolved in Brazil from 1970 e 2006. The idea was to introduce a conceptual discussion on the relations between "opportunity structures", "political processes", and "individual involvement" in the emergence of mobilizations and collective protests. The methodology consisted of biographical interviews with three different generations of activists, focusing on the meanings associated with the use of academic training in activism, the principal modalities of militant careers, and the types of resources and social ties that support the activists' concepts and practices. The research showed that the period under study constitutes a milestone for the emergence of new patterns for reconverting university and professional training into militant resources for action in the "environmental field".

Key words: opportunity structures; political processes; individual involvement; activism; environmentalism

\section{RÉSUMÉ}

\section{Genèse et Redéfinitions du Militantisme Écologique au Brésil}

Dans cet article, on examine les conditions du surgissement et des transformations du militantisme écologique au Brésil de 1970 à 2006. On cherche à discuter les concepts à partir des relations entre "structures d'opportunité", "processus politiques" et "engagement individuel" dans l'apparition de mobilisations et manifestations collectives. L'approche méthodologique se fait par des entretiens biographiques avec trois générations différentes d'activistes, afin d'examiner les significations associées à l'usage de la formation scolaire dans la militance, les principales modalités des carrières des militants et les types de moyens et de liens sociaux qui supportent les concepts et pratiques militantes des activistes. D'après la recherche, la période étudiée représente un point de surgissement de nouveaux modèles de transformation de la formation universitaire et professionnelle en ressources militantes pour agir dans "le domaine de l'environnement".

Mots-clé: structures d'opportunités; processus politiques; engagement individuel; militantisme; écologie 